\title{
Improving How Evolution Is Taught: Facilitating a Shift from Memorization to Evolutionary Thinking
}

\author{
Timothy R. Frasier • Carol Roderick
}

Published online: 8 April 2011

(C) Springer Science+Business Media, LLC 2011

\begin{abstract}
In North America, public understanding and acceptance of evolution is alarmingly low. Moreover, acceptance rates are declining, and studies suggest that even students who have taken courses in evolution have the same misunderstandings as the general public. These data signal deficiencies in our educational system and provide a "call to arms" to improve how evolution is taught. Many studies show that student education can be improved by replacing lecture-based pedagogy with active learning approaches-where the role of students changes from passive note taking to active problem solving. Here, we describe changes made to a second-year undergraduate evolution course to facilitate a shift to active learning and improve student understanding of evolution. First, lectures were used only sparingly and were largely replaced by problem-solving activities. Second, standard textbooks were replaced by "popular" books applying evolutionary thinking to topics students encounter on a daily basis. Lastly, predefined laboratory exercises were replaced by student-designed and implemented research projects. These changes led to increased student engagement and enjoyment, improved understanding of evolution and ability to apply evolutionary thinking to biological problems, and increased student recognition that evolutionary thinking is
\end{abstract}

T. R. Frasier $(\bowtie)$

Department of Biology, Saint Mary's University,

923 Robie Street, Halifax,

Nova Scotia B3H 3C3, Canada

e-mail: timothy.frasier@smu.ca

C. Roderick

Centre for Academic and Instructional Development (CAID),

Saint Mary's University,

923 Robie Street, Halifax,

Nova Scotia B3H 3C3, Canada important not only in the classroom but also in their daily lives.

Keywords Active learning · Problem-based learning . Teaching strategies $\cdot$ Science education $\cdot$ Teaching evolution $\cdot$ Undergraduate education

\section{Introduction}

It is well known, and widely publicized, that the acceptance rate of evolution in North America is woefully low (Miller et al. 2006). Indeed, a Gallup Poll held on the eve of Darwin's 200th birthday showed that only 39\% of Americans say they "believe in the theory of evolution" (Newport 2009). This is down from $45 \%$ in 1985, resulting in the United States having the second lowest acceptance rate out of 34 countries surveyed (Miller et al. 2006). Meanwhile, acceptance rates in many other countries exceed 75\% (e.g., Iceland, Sweden, Denmark, France, Japan) (Miller et al. 2006). This lack of acceptance is often attributed to the high degree of fundamentalism, and the linking of religious and political views in North America (Miller et al. 2006; Mooney 2005; Paterson and Rossow 1999). Although these data are distressing, what should be an even larger cause of alarm are data suggesting that students majoring in biology and/or who have taken courses in evolution fare no better than the general public, graduating with the same misunderstandings of evolution as when they began university (Alters and Nelson 2002; Sundberg and Dini 1993). This problem is particularly alarming because evolution is the unifying concept of biology, and therefore, misunderstandings of evolution will likely lead to difficulties and misconceptions in all other biology courses. Combined, these data highlight the 
deficiencies in our education systems and serve as a compelling call to action to improve how evolution is taught.

These educational deficiencies are not unique to the topic of evolution, and there is now a wealth of literature showing that science education, as a whole, needs renovation (Alberts 2009; Handelsman et al. 2004; Powell 2003). The picture emerging from education research is that the typical lecture-based format of teaching and cookbook-like laboratory exercises do not promote critical thinking or deep understanding. Instead, this approach tends to award students who are good at memorization and therefore may perform well on tests, but who may not have a basic understanding of the topic (Alberts 2009; Lord 1998; Powell 2003; Walker et al. 2008).

A new approach to teaching was developed and applied at the McMaster University medical school (Hamilton, Ontario) in 1969. There, lectures were abolished, and the class structure consisted of students solving problems in small groups - having to identify for themselves what they needed to learn to solve the problem and then go about learning it (Barrows and Tamblyn 1980). This approach was called problem-based learning (PBL), and its goal was to help students develop the skills necessary not only to address the problem at hand but also facilitate a lifetime of continuing education. The rationale is that in order to stay relevant, medical students (and all scientists) must be in a continual educational process, being able to identify where their gaps in knowledge are and filling them as needed. This need does not diminish upon graduation from medical school or university. Thus, PBL would not only provide the necessary educational foundation required from a medical school but would also teach students to "learn how to learn," resulting in doctors more able to deal with the changing field of medicine over time. Moreover, it was also hoped that this approach would be more fun, increasing student and teacher satisfaction in the educational process (Barrows and Tamblyn 1980).

Problem-based learning has been a huge success and is now used in several medical schools, universities, and K-12 schools (Duch et al. 2001). Several similar teaching approaches have also been developed and applied, with a similar emphasis on student-led inquiry. These teaching strategies can generally by classified as "active learning" approaches, where the focus is shifted from teaching to learning. In these classes, the teacher is no longer the "deliverer of facts" to be learned by the students but instead facilitates an environment where students feel comfortable and have the opportunity to solve problems on their own. Such a pedagogical approach is ideal for science courses because science is a process rather than a series of facts to be memorized. Having students learn through a scientific process of problem solving not only teaches them the subject at hand but also other desirable skills in the sciences such as critical thinking, hypothesis testing, and how to work in collaborative groups (Clark et al. 2009; Ebert-May et al. 1997; Herreid 1998; Mayer 1984).

A large number of studies have now compared the performance of students in active learning environments with their lecture-based counterparts. In terms of academic performance, students in active learning courses perform just as well, and often better, on exams than students in lecture-based courses (Armbruster et al. 2009; Herreid 1998; Walker et al. 2008). Perhaps more importantly, students in active learning environments show greater retention of information, enjoy the classes more, and show improved critical thinking and problem solving skills (Armbruster et al. 2009; Ebert-May et al. 1997; Nelson 2008; Walker et al. 2008). But despite this wealth of data, educators have been slow to implement these teaching methods, and lecture-based courses predominate in most university classrooms. The reasons for this lack of change vary widely, but perhaps the most common one is that most educators are not aware that alternative teaching methods exist (Herreid 1998). Many scientists do not read the educational literature and therefore are unaware of the compelling data showing the benefits of changing their pedagogical approach. This leads to an interesting dichotomy, where some professors take a very scientific approach to research - staying on top of the literature and changing their hypotheses and research strategies accordingly-but maintain a very unscientific approach to the evaluation and improvement of their teaching (Herreid 1998).

Here we describe changes made to a second-year undergraduate evolution course at Saint Mary's University (Halifax, Nova Scotia) to help address these issues and improve student learning in evolution and the scientific process. In addition to improving student understanding of evolution, a major goal was also to show students that evolution is not just one of many topics in biology but rather that evolutionary thinking - approaching biological topics from an evolutionary perspective-is key to appropriately addressing any biological question, including those relating to humans. Therefore, we wanted to promote students' applying evolutionary thinking not just in the classroom but in their day-to-day lives as well. To facilitate this type of learning and thinking, we made three primary changes to the general course structure. Many of these changes were motivated by, and modeled after, similar approaches recently applied by Madhuri and Broussard (2008) to improve a developmental biology course at the University of La Verne (La Verne, California).

First, lectures were used sparingly and only to introduce new concepts and ideas. Instead, a large portion of each class period was dedicated to active learning activities, where students worked through problems associated with 
the new material. Second, instead of a general textbook on evolution, two "popular" books were used that apply evolutionary thinking to topics that students encounter and/or hear about in their day-to-day lives: human health and homicide. The two books chosen where Why We Get Sick: The New Science of Darwinian Medicine (Nesse and Williams 1994) and Homicide (Daly and Wilson 1988), respectively. The goal here was to engage students by showing how evolutionary thinking is relevant to human biology and behavior and to promote evolutionary thinking in topics they encounter on a daily basis. Lastly, instead of predefined lab projects, students worked in groups to design and implement their own research projects within the limits of bacterial resistance to available chemicals/ products. The goal of this process was to get students thinking and acting like scientists, learning how science works, and learning how to apply the scientific method to test an evolutionary hypothesis.

\section{Methods}

\section{The Course}

This new teaching approach was tested on the students enrolled in evolution at Saint Mary's University in the winter term of 2010. Evolution is not a required course for biology majors, but many students take it as one of their selected courses to meet the required number of credits in biology. During this term, 27 students were enrolled: 11 males and 16 females. The class consisted of two 75-minute lecture periods and one three-hour laboratory period each week.

\section{Changes to Lecture}

Although our goal for this course is to make it completely problem-based, at the moment, there is still a lecture component. But lectures were used sparingly. The first half of most class periods was spent in a typical lecture format, where new information and concepts were discussed. When appropriate, the new concepts were then applied to at least one example from non-human organisms and one from humans to try to show students how this new information/concept applies to both general and human biology. The second half of the class usually involved problem-based activities to challenge and engage students to start applying this concept themselves and/or videos or other media to provide a different perspective and alternative stimuli.

At the beginning of the term, the students were divided into small working groups of four to seven students each. When the introduction part of the class was over, the students would divide into these groups to work on a problem related to the new concepts discussed. When possible, each group worked on a different problem relating to the same general principles, but in some cases, all groups worked on the same problem. When each group worked on a different problem, after approximately ten minutes of group work, a member of each group would come to the front of the class, read the problem aloud, and discuss their group's solution. This would lead to class discussion on the specific problem, as well as the general topic. When all groups worked on the same problem, one group was randomly chosen to present their approach to solving the problem and their solution. At every step of the process, we would discuss if other groups approached the problem in the same manner and/ or came to the same conclusions. This led to class discussion and an eventual consensus on the best way to approach the problem, as well as the potential solution.

The goals of these group sessions were twofold. First, we wanted to transform student behavior from passively taking notes in class to actively thinking about the concepts being discussed and applying that thinking to solve problems. The rationale was that this approach should facilitate students actually learning the information and gaining practice applying it to real-life situations, rather than simply memorizing it. Second, we wanted to give students a safe, encouraging, and supportive environment for them to practice applying evolutionary thinking to biological issues, with the hope that by the end of the term, this would become natural.

\section{Changes to Textbooks}

Although excellent textbooks and associated materials exist for teaching evolution at the university level (e.g., Freeman and Herron 2007; Futuyma 2006), we thought that student engagement would be higher if we used books that: (1) represented the "popular" literature more and were books that students might read for fun on their own and/or pass on to friends and family; and (2) applied evolutionary thinking to human issues that the students experience and/or hear about on a day-to-day basis. The two books that we chose were Why We Get Sick: The New Science of Darwinian Medicine (Nesse and Williams 1994) and Homicide (Daly and Wilson 1988).

The first hour of each laboratory period was devoted to student-led discussions based on assigned readings (approximately three chapters each week) from these books. The students led these discussions in groups of three to four students, keeping the same groups as for their laboratory work. Both of the books are relatively old, which was advantageous because the students were then encouraged to read the scientific literature relating to these topics and provide the class with an update on 
what research has been conducted since the book was published. After a brief summary of the readings and a presentation of recent advances in the relevant topics, the groups developed questions and were charged with leading a class discussion on these topics for an hour.

\section{Changes to Laboratory Sessions}

Perhaps the largest change to the course was in the laboratory sessions. Students were not given predefined lab exercises or projects. Instead, they worked in groups to create and conduct their own projects within the limits of bacterial resistance to available chemicals/products. The goal was for the students to see evolution in action and develop experiments that would result in the bacteria's evolving increasing resistance to whatever external pressure the students applied. These lab sessions were divided into a three-step process. The first few weeks of the term were dedicated to proposal development. Here, the students worked in their groups to identify a research question they wanted to investigate, perform enough background research so that they could design an appropriate experiment, and then develop a research proposal for this work. Each group then presented their research proposal-including background information, hypotheses and predictions, and research design - for peer review by the class. The rest of the students then had the opportunity to comment on how protocols could be improved and/or question the rationale behind different steps. Any gaps in the protocols could also be identified and improvements suggested on how to increase the probability of success.

The second step involved conducting the experiments, where each group applied their research design to address their research question and test their hypotheses, modifying protocols and approaches as needed. The students also had to plan ahead and provide a list of needed materials for each laboratory session, so that these could be gathered and prepared in time. Lastly, the students had to analyze and interpret their data, present their results to the class, and write a lab report in the form of a scientific paper.
The goals of changing the laboratory sessions in this way were twofold. First, we wanted the students to actually observe evolution within the timeframe of one semester. Bacteria are ideal for this due to their extremely short generation time and the ease with which they can be used in the laboratory. Second, we wanted the students to get practice in thinking and acting like scientists, learning how science works, and learning how to apply the scientific method to test an evolutionary hypothesis. Having them develop and write research proposals, participate in the peer review process, conduct their research and modify approaches as needed, and analyze and interpret results captures the major activities of scientists, providing a more realistic scientific experience than following predefined exercises.

\section{Evaluation}

To evaluate the success of these pedagogical changes in improving how students understand and think about evolution, we used two approaches: questionnaires conducted on the first and last days of class and focus group discussions that took place at the end of the term. On the first and last days of class, the students completed the revised version of the "conceptual inventory of natural selection" (CINS) questionnaire developed by Anderson et al. (2002), which can be downloaded from http://www.biologylessons.sdsu.edu/ CINS6_03.pdf. This is a 20-question evaluation carefully designed to evaluate how students think through evolutionary problems. These questions are ideal for evaluating how students apply evolutionary thinking to biological problems, where performance cannot be improved just through the memorization of information. The questionnaire also contained six questions we developed that capture the primary misconceptions students tend to have regarding evolution (Table 1). These were included to identify which misconceptions were common among the students so that they could be dealt with directly throughout the term. Additionally, they were useful in assessing how student misconceptions changed as a result of the course. Lastly, the questionnaire contained three questions, modified from

Table 1 True/False questions used to identify student misconceptions about evolution

1. An individual can evolve within its lifetime.

2. Evolution is called a "theory" because there is still debate about it in the scientific community.

3. Charles Darwin was the first person to propose the idea of evolution.

4. Evolution is a progressive process that works like a ladder, with less-evolved organisms on the lower rungs and more-evolved organisms on the higher rungs. We can therefore refer to "higher" and "lower" organisms.

5. Humans evolved from chimpanzees.

6. Evolution is essentially "chance."

These six questions were part of the questionnaire completed on the first and last days of class to identify how student misconceptions changed throughout the term 
Gregory and Ellis (2009), to evaluate how students perceived their understanding of evolution and its importance to biological issues (Table 2).

Performance on these questionnaires was not included as part of the student grades: these data were collected solely for the purpose of evaluating the pedagogical approach. This was made clear to the students at the beginning of the term. To ensure anonymity during these questionnaires, the professor (TRF) was not present while they were being completed. Instead, a member of the Centre for Academic and Instructional Development administered the questionnaires and developed a coding system where names were replaced with codes on the questionnaires. Thus, there was no way for the instructor to know which student was linked to which questionnaire, but such information was available to the co-researcher.

At the end of the term, students voluntarily participated in focus groups to discuss what they liked and did not like about the course, what they thought about the new teaching strategies, whether or not the way they think about evolution had changed, and if they saw evolution as being more important in their day-to-day lives than prior to taking the course. These discussions were recorded on audiotapes and subsequently transcribed to electronic files. As with the questionnaires, the instructor was not present during the focus groups, and a coding system was developed so that he could not link specific responses to individual students. Access was given only to the coded transcribed data, and the audiotape and initial transcription were kept by the co-researcher.

All data analyses and visualization were conducted with R (R Development Core Team 2009). Comparisons of means were based on $t$ tests after ensuring that the distributions being compared did not differ significantly from the normal distribution (Kolmogorov-Smirnov tests) and did not differ significantly in their variances (Fisher's $F$ tests). Comparisons of count data were tested for significance using Fisher's Exact Tests.

\section{Results}

The questionnaire data showed that students entered the course with several misconceptions of evolution, with an average of only $47 \%$ of correctly answered questions (Fig. 1a). This average changed dramatically throughout the course, with the average of correctly answered questions jumping to $77 \%$ in the second questionnaire (Fig. 1a; $t$ test, $P=4.43 \times 10^{-7}$ ). Similarly, the students' ability to use evolutionary thinking to solve biological problems improved significantly, as indicated by the Concept Inventory questionnaire data. Here, the average number of correct answers increased from $60 \%$ before the course to $73 \%$ after (Fig. $1 \mathrm{~b}$; $t$ test, $P=0.0202$ ).

Not surprisingly, the students felt that their understanding of evolution improved significantly from the course

Table 2 Questions used and/or modified from Gregory and Ellis (2009) used as part of the questionnaire

1. In your opinion, how well do the following people understand evolution? $(1=$ not at all, $5=$ very well $)$

A-You

\begin{tabular}{|c|c|c|c|c|}
\hline 1 & 2 & 3 & 4 & 5 \\
\hline \multicolumn{5}{|c|}{ B-Fellow students in your program } \\
\hline 1 & 2 & 3 & 4 & 5 \\
\hline \multicolumn{5}{|c|}{$\mathrm{C}-$ Members of the general public } \\
\hline 1 & 2 & 3 & 4 & 5 \\
\hline
\end{tabular}

2. How relevant do you think evolutionary thinking is for the following? ( $1=$ irrelevant, $5=$ very relevant $)$

A-Your day-to-day activities

$1 \quad 2 \quad 3 \quad 4 \quad 5$

B-The field that you are majoring in or the career you hope to have

$\begin{array}{lllll}1 & 2 & 3 & 4 & 5\end{array}$

C-Scientists trying to understand the natural world

$1 \quad 2 \quad 3 \quad 4 \quad 5$

3. How strongly do you agree with the following statements? ( $1=$ disagree, $5=$ strongly agree $)$

A-The meaning of the word "theory" differs considerably in science versus in common language

$1 \quad 2 \quad 3 \quad 4 \quad 5$

B-In science, what begins as a "theory" may be promoted to being considered "fact" once there is overwhelming evidence to support it

$\begin{array}{lllll}1 & 2 & 3 & 4 & 5\end{array}$

C-In science, "theories" do not become "facts, but rather theories explain facts"

1

23

4

5 

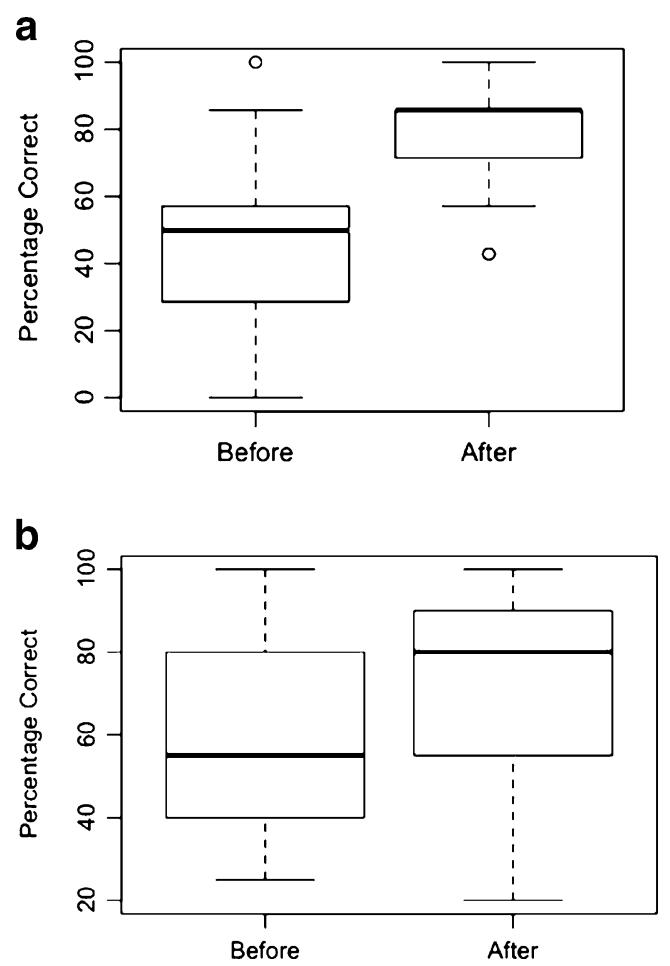

Fig. 1 Box plots showing the distribution of correct answers to: a the "common misconceptions" questions and b the Concept Inventory questions in the questionnaire before and after taking the course. The dark line represents the mean, the box encapsulates the middle $50 \%$ of the data, the vertical dashed lines span two standard deviations of the data, and the dots indicate outliers (values falling more than 1.5 times above the third quartile or below the first quartile)

(Fig. 2a; Exact Test, $P=0.0270$ ). They also thought that the general public's understanding of evolution was fairly low, with this perception not changing throughout the term (Fig. 2b; Exact Test, $P=0.509$ ). Statistical analyses suggest that taking the course did not significantly influence how important the students felt evolution was to their day-to-day lives (Fig. 2c; Exact Test, $P=0.962$ ). But this result from the questionnaire data conflicts with data from the focus groups, where one of the primary comments was how the course changed the way the students thought about other topics in their lives. Representative quotes are provided in Table 3.

The students found the changes to the "lecture" aspect of the class much more engaging than typical lectures. They enjoyed having the opportunity to think through situations and gain experience applying evolutionary thinking to different scenarios. Ensuring that examples from humans were used, in addition to those from non-human organisms, also seemed to make the class more engaging (Table 4).

Students were much more engaged by the use of "popular" books as opposed to a standard textbook, suggesting that this strategy is beneficial. However, the two books received opposing reviews. There was great enthusiasm for Why We Get Sick, which clearly had a lasting effect on the students. But they did not like Homicide. Although the students seemed to find the topic interesting, many did not like the writing style and found it difficult to follow. Some also commented that they could not really relate to the topic, which could have limited student engagement (Table 5).

The changes to the laboratory approach received mixed reviews. Overall, the students seemed to get much more out of the laboratory sessions than in a standard setting based on cookbook-like lab manuals. But not having a defined protocol to follow or specific results to expect made many of the students uncomfortable, which is a typical response
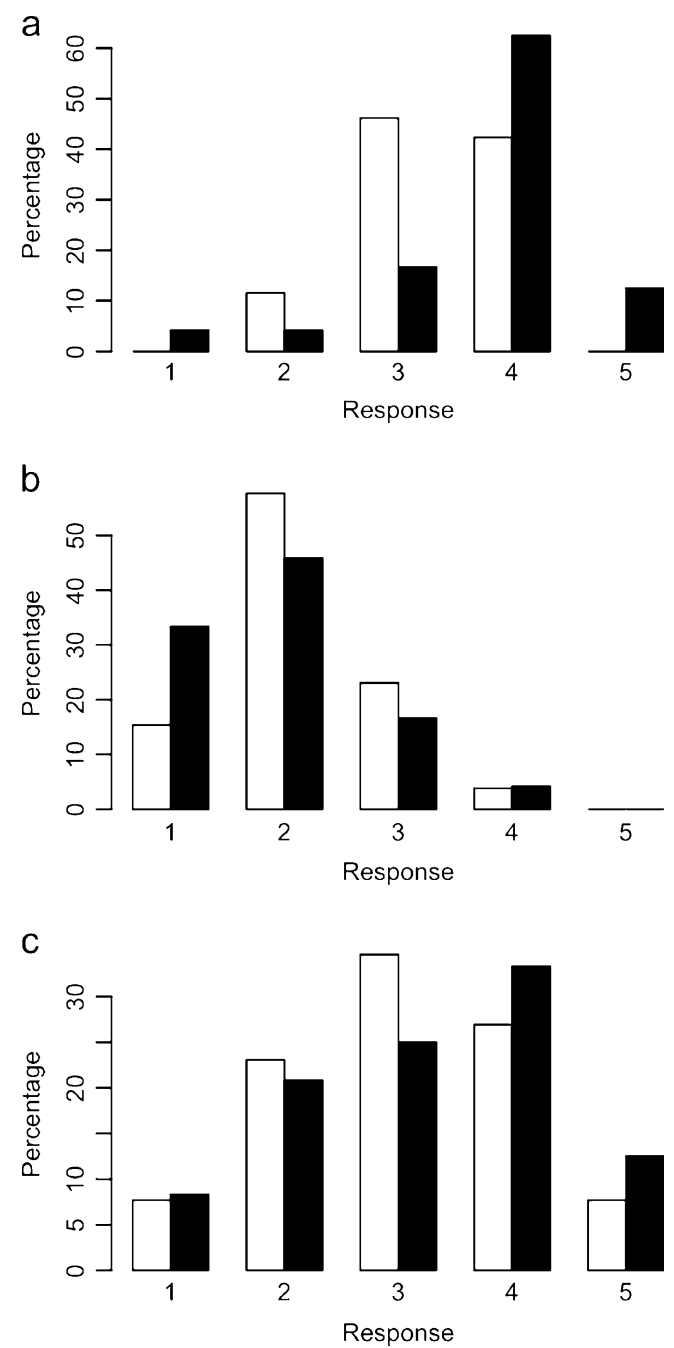

Fig. 2 Bar plots showing how students rated: a how well they understand evolution; b how well they think the general public understands evolution; and $\mathbf{c}$ how relevant they think evolutionary thinking is to their day-to-day activities. All responses were ranked on a scale from 1 (lowest) to 5 (highest) - see Table 2 for details. White bars represent results from the initial questionnaire and black bars represent results from the questionnaire administered on the last day of class 
Table 3 Representative quotes from the focus groups suggesting that taking the course demonstrated the importance of applying evolutionary thinking to their day-to-day lives

“This class completely changed my thinking. I wasn't really interested in evolution. I thought it was insignificant. But my imagination and my interest rose significantly."

"I kind of related it to everything I do now. I'm at the bar and seeing that everything you do is related to getting ahead. It's so just set up in the back of our minds, we're always thinking about promoting fitness and stuff, but you'd never really think about it until now."

"I'm in a cell biology 2 course and we were learning about cancer. I was in class and thinking about how does this cancer cell, how do all of these mutations benefit this cancers cell? I was like 'wait a second, what am I doing?' I was thinking about it from an evolutionary perspective. I thought about it then; I was really applying the stuff and I'm going home and I'm telling my parents about cool stuff that we've learned in class and am like 'Did you know this?!' and they're like 'No.' 'Well now you do!'”

“...colds have always been around since humans have been around so we must have defenses, just let them work. Fever is a defense. I had no idea, I thought fever was a symptom and something that was not good but it speeds up your metabolism and helps you heal better."

Quotes are direct, without an attempt to improve wording, grammar, or clarity

of students who are new to PBL approaches (e.g., Sahin 2010). While they recognized that this is how science works, it made them uneasy as to what was expected of them and how they would be graded (Table 6).

\section{Discussion}

Overall, the changes to the course were very effective: increasing student engagement, improving their understanding of evolution, facilitating the application of evolutionary thinking to topics outside of the classroom, and increasing overall enjoyment of the course. But there are clearly areas where the course can be further improved.

It was surprising that at the end of the course, the average score on the "common misconceptions" questionnaire was not higher than $77 \%$. It was fully expected that all students would answer these questions correctly by the end of the term. A closer look at the data shows that two misconceptions were still prevalent. At the end of the term, $33 \%$ of the students correctly answered "FALSE" to the misconception that "Evolution is essentially "chance"; and only $58 \%$ correctly answered "FALSE" to the misconception that "Evolution is called a 'theory' because there is still debate about it in the scientific community." These represent fundamental misconceptions of evolution that remained despite being explicitly dealt with throughout the course. From these data, it is clear that these misconceptions are deeply rooted, and their rectification requires more effort than was given here despite being directly dealt with via class discussions and problem-based exercises.

Recent studies have shown that altering student misconceptions of fundamental concepts can require particular attention, because these concepts form the foundation on which students have perceived and interpreted the world (e.g., Duit and Treagust 2003; Nelson 2008). Thus, revising these concepts requires a fundamental shift in student thinking, and these misconceptions need to be dealt with in a more systematic manner. Studies suggest that this is most successful when the students are faced with a scenario in which they will recognize, for themselves, the inadequacies of their current (incorrect) understanding and then reach the correct conclusions on their own (Duit and Treagust 2003; Nelson 2008). We are currently working to devise such scenarios for dealing with common misunderstandings of evolution, which will be used in the upcoming term.

It was also surprising that although performance significantly improved on the concept inventory questions, the variance remained the same before and after the course (Fig. 1b), indicating that the performance of some students did not improve at all. But closer examination of these data

Table 4 Representative quotes from the focus groups regarding their thoughts on the changes to the lecture aspect of the class

\footnotetext{
"He encourages student discussions and it helps you remember the things if you are participating. Actually I think this is the first course at Saint Mary's where I attended every single class."

"I like that I'm actually taking something away from it and I enjoy going to class. At the same time it's really hard. It is very demanding."

"He gives you information then asks you your opinion on it and gets you to think about it instead of just the regular method, which doesn't work."

"He used examples which we could relate to, and if he was ever talking about animals he would make some kind human comparison both in the lab and in class, which is interesting. We were just talking about bar fights, now we know why they happen: because of male competition, alcohol is a social lubricant, it helps everything happen. Men are competing."

"I think we are coming out of this course ten times better than we would be coming out of it if we were taking it with another professor that just had multiple choice tests where you'd just regurgitated information. We're applying it, which is good. The way he teaches, he's definitely on to something really good, but there's definitely some fine tuning."
} 
Table 5 Representative quotes from the focus groups regarding student thoughts on the use of popular books in the course, and their thoughts on each of the chosen books

"Normally, when I get a textbook it's like I still haven't broken the seal, but I actually read it [Why We Get Sick] and I found it interesting. I was like 'whoa Dad!' [sounds of the group agreeing and laughing] I told all my friends and they were like 'That's so cool!"”

"Like I told my dad to read it. I thought Why We Get Sick was good. I didn't really read that much of Homicide, enough for the presentation."

"I think the Why We Get Sick book really did it. It relates to the present, not just facts about evolution in the past or like the history, it's in our society today."

"Homicide is interesting to learn about but all the statistics in the book, the majority of the chapter is statistics and I want to skip through it but then I feel that later they are going to relate to but it's so boring I can't actually sit down and read it. I have to walk away from the book, come back, walk away, come back, it's just annoying."

"How many of us can relate to homicide, it's more observational then participatory."

shows that this lack of change may be due to a few students who did not attend many classes and did not perform well in the class overall.

Minimizing the lecture component of the course, and focusing instead on active learning activities such as problem solving and discussion, achieved the desired goals of transforming student behavior from passive note taking to active thinking and facilitated evolutionary thinking to biological questions. This was evident from the focus group discussions (Tables 3 and 4), teacher evaluation forms (not shown), and general discussions with the students. Moreover, the students seemed to genuinely enjoy the class more, which was reflected in the high attendance rates (see Table 4), and in discussions with the students by both authors. Despite this progress, we would like to continue shifting the course toward a completely problembased format. At the moment, lectures are still used to introduce new ideas and topics, which then form the basis of subsequent discussions and problem sets. We recognize that this approach is not true problem-based learning, where the problem comes first and the students have to decide for themselves what ideas and topics need to be learned to address the problem (Barrows and Tamblyn 1980). To achieve this, we are working toward developing appropriate problems for different topics in evolution that would be appropriate, and these will be integrated into the course as they are developed.

The idea of using popular books to encourage evolutionary thinking was not only clearly successful but also demonstrated the importance of book selection. Using popular books applying evolutionary thinking to human topics achieved the goals of increasing student engagement and facilitating students' actually doing the assigned readings (Table 5). It also had the desired effect of students' applying evolutionary thinking to some topics in their dayto-day lives (Table 3). But although all reviews of Why We Get Sick were extremely positive, all reviews of Homicide were negative - not because of content but because of the writing style. It is possible that this book is written at an academic level above what should be expected for secondyear student comprehension. We think that Homicide provides an excellent example of the importance of applying evolutionary thinking to human behavior and societal issues. However, because of the negative reviews, in the future, these topics will form the basis of class discussions and/or group problems, as opposed to assigned readings. We are currently trying to find a book to replace Homicide for the assigned readings. It is clear that to engage students, the book needs to involve humans and issues that students encounter on a daily basis. An obvious possibility would be a book applying evolutionary thinking to human sexuality, of which there are many (e.g., Diamond 1998; Ridley 2003).

The students were initially caught off-guard with the changes to the laboratory experiments and were unsure about developing their own research questions and designing their own experiments. But as the course progressed, and they gained confidence in their ability to conduct their own research, they seemed to appreciate the experience of

Table 6 Representative quotes from the focus groups regarding student thoughts on the changes made to the laboratory portion of the course

"It was the first time I ever had a lab where it was 'for this lab you are going to make your own experiment and make bacteria evolve.' So I was like 'I don't know...' I thought the course was going to be a lot easier, but I'm glad I took it."

"It was a learning curve. I learned from a lot of my mistakes [general agreement]. In that sense it was a not a failure in the end. I got some results but at the same time all the failures added to my understanding."

"That's the whole point though, that's science. That's what annoys me about every other class. You follow the guidelines then don't get anything out of it. Science doesn't work like that."

"I don't think he's going to mark whether or not we were successful. Definitely not, but a lot of people were thinking that. They have to get it out of their minds. It's the process that you're going through that you're getting marked on. The fact that you're going through the hit and miss and everything like that. That was great." 
gaining real practice as scientists (Table 6). Indeed, the students came to enjoy the laboratory sessions, and many expressed frustration with the standard "protocol-driven" labs used in many other courses, noting that students tend not to learn much from those experiences (Table 6). From a teaching perspective, it was very encouraging and satisfying to see the students develop throughout the term. Because the results of their experiments were completely dependent on the students themselves, they quickly switched from a passive role to an active role and were therefore engaged and invested in their projects. This process also promoted critical thinking skills. Because they had limited time for their experiments, the students were very wary of basing their experiments on information unless they were sure it was correct and would lead to the desired results. Overall, this change to the laboratory sessions was very successful, leading to increased student engagement and enthusiasm, while also giving students the opportunity to gain practice with the scientific method and realize the importance of critical thinking (Table 6).

One downside to this change to the laboratory sessions was student concern regarding how they were being graded (Table 6). Since students are typically graded on the outcome of their laboratory experiments, that is also what they expected here. This raised student concerns because now, in addition to getting "good" results, they also had to develop their own experiments - many of which did not work quite as planned and had to be modified throughout the term. But we were more interested in the process rather than the outcome; therefore, students were graded on how well they applied the scientific method to address their research question. Thus, the outcome of their experiments was irrelevant, as long as the students were able to show that they could design appropriate experiments, implement them, and identify how they needed to be modified to meet their research objectives. The students seemed to have trouble grasping this idea of being graded on the process rather than the outcome. Similar findings of student concern over instructor expectations have been reported in other cases where active learning exercises have replaced more classical teaching approaches (e.g., Walker et al. 2008). So it is clear that in the future, we will need to work harder to clarify the expectations and grading scheme for the laboratory sessions.

One of the main goals of the course was to promote students' applying evolutionary thinking to their day-to-day lives. Unfortunately, the data regarding whether or not this goal was achieved are ambiguous. On the one hand, the students' response to the questionnaire question of how important they thought evolutionary thinking was to their day-to-day activities (Table 2) suggests that their answer did not significantly change throughout the course (Fig. 2c). Although a clear shift in the distribution of their responses is evident (Fig. 2c), this shift was not statistically significant (Exact Test, $P=0.962$ ). On the other hand, one of the primary comments during the focus groups was how, after taking the course, the students found themselves applying evolutionary thinking to different aspects of their daily lives (e.g., Table 3). The reasons for these conflicting results are not clear. But the comments from the focus groups clearly show that the course did promote the students' applying evolutionary thinking to their daily lives, at least to a certain extent. We therefore think that this goal was met but are working to further improve on this in the future.

Overall, these changes to the lecture format, readings, and laboratory sessions had the desired outcome of shifting the role of students from passively taking notes and following protocols to actively applying evolutionary and scientific thinking to the course and their daily lives. The students also seemed to enjoy the class more and were engaged in the topics being discussed. The data suggest that these changes also improved student understanding of evolution and their ability to think through biological problems from an evolutionary perspective. While these changes had the desired outcomes, further improvements of the course are ongoing, including continuing a shift to a fully problem-based format and identifying appropriate texts.

Acknowledgements We would like to thank the students of this evolution course for approaching this course, and teaching approach, with open minds and for participating in all of the questionnaires and focus groups. We would also like to thank Natasha Ching for help with literature searches and transcribing the focus group discussions and Brenna McLeod for helpful comments that improved the manuscript. This work was funded by the Centre for Academic and Instructional Development at Saint Mary's University.

\section{References}

Alberts B. Redefining science education. Science. 2009;323:437.

Alters BJ, Nelson CE. Teaching evolution in higher education. Evolution. 2002;56:1891-901.

Anderson DL, Fisher KM, Norman GJ. Development and evaluation of the conceptual inventory of natural selection. J Res Sci Teach. 2002;39:952-78.

Armbruster P, Patel M, Johnson E, Weiss M. Active learning and student-centered pedagogy improve student attitudes and performance in introductory biology. CBE Life Sci Educ. 2009;8:203-13.

Barrows HS, Tamblyn RM. Problem-based learning: an approach to medical education. New York: Springer; 1980.

Clark IE, Romero-Calderón R, Olson JM, Jaworski L, Lopatto D, Banerjee U. "Deconstructing" scientific research: a practical and scalable pedagogical tool to provide evidence-based science instruction. PLoS Biol. 2009;7:e1000264.

Daly M, Wilson M. Homicide. New Jersey: Transaction; 1988.

Diamond J. Why is sex fun? the evolution of human sexuality. New York: Basic Books; 1998.

Duch BJ, Groh SE, Allen DE. The power of problem-based learning. Stylus: Virginia; 2001. 
Duit R, Treagust DF. Conceptual change: a powerful framework for improving science teaching and learning. Int $\mathrm{J}$ Sci Educ. $2003 ; 25: 671-88$

Ebert-May D, Brewer C. Allred S (1997) Innovation in large lectures teaching for active learning. Bioscience. 1997;47:601-7.

Freeman S, Herron JC. Evolutionary Analysis. 4th ed. New Jersey: Pearson Prentice Hall; 2007.

Futuyma DJ. Evolution. 3rd ed. Sunderland: Sinauer; 2006.

Gregory TR, Ellis CAJ. Conceptions of evolution among science graduate students. Bioscience. 2009;59:792-9.

Handelsman J, Ebert-May D, Beichner R, Burns P, Chang A, DeHaan R, et al. Sci teaching Science. 2004;304:521-2.

Herreid CF. Why isn't cooperative learning used to teach science? BioScience. 1998;48:553-9.

Lord T. Cooperative learning that really works in biology teaching: using constructivist-based activities to challenge student teams. Am Biol Teacher. 1998;60:580-8.

Madhuri M, Broussard C. "Do I need to know this for the exam?" Using popular media, inquiry-based laboratories, and a community of scientific practice to motivate students to learn developmental biology. CBE Life Sci Educ. 2008;7:36-44.

Mayer WV. The arrogance of ignorance-ignoring the ubiquitous. Am Zool. 1984;24:423-31.

Miller JD, Scott EC, Okamoto S. Public acceptance of evolution. Science. 2006;313:755-6.

Mooney C. The Republican war on science. New York: Basic Books; 2005.
Nelson CE. Teaching evolution (and all of biology) more effectively: strategies for engagement, critical reasoning, and confronting misconceptions. Integr Comp Biol. 2008;48:213-25.

Nesse RM, Williams GC. Why we get sick: the new science of Darwinian medicine. New York: Vintage; 1994.

Newport F. On Darwin's birthday, only 4 in 10 believe in evolution. (February 11, 2009) Available online at http://www.gallup.com/ poll/114544/Darwin-Birthday-Believe-Evolution.aspx.

Paterson FRA, Rossow LF. "Chained to the devil's throne": evolution $\&$ creation science as a religio-political issue. Am Biol Teacher. 1999;61:358-64.

Powell K. Spare me. lecture Nature. 2003;425:234-6.

R Development Core Team. R: A language and environment for statistical computing. R Foundation for Statistical Computing, Vienna, Austria. ISBN 3-900051-07-0, URL http://www.R-project. org; 2009.

Ridley M. The Red Queen: sex and the evolution of human nature. New York: Perennial; 2003.

Sahin M. Effects of problem-based learning on university students' epistemological beliefs about physics and physics learning and conceptual understanding of Newtonian mechanics. J Sci Educ Technol. 2010;19:266-75.

Sundberg MD, Dini ML. Science majors versus nonmajors: is there a difference? J Coll Sci Teaching. 1993;23:299-304.

Walker JD, Cotner SH, Baepler PM, Decker MD. A delicate balance: integrating active learning into a large lecture course. CBE Life Sci Educ. 2008;7:361-7. 